\title{
Incluir não é Apenas Socializar: as Contribuições das Tecnologias \\ Digitais Educacionais para a Aprendizagem Matemática de Estudantes com Transtorno do Espectro Autista
}

\author{
Inclusion is not Only Socialization: Contributions of Digital Educational \\ Technologies to the Mathematical Learning of Students with Autistic \\ Spectrum Disorders
}

\author{
Andiara Cristina de Souza* \\ ORCID iD 0000-0003-0160-6488 \\ Guilherme Henrique Gomes da Silva** \\ ORCID iD 0000-0002-4166-2663
}

\begin{abstract}
Resumo
A inclusão de estudantes com Transtorno do Espectro Autista (TEA), embora devidamente amparada pela legislação brasileira, representa um grande desafio para as escolas regulares de ensino e está longe de ser uma realidade. A inclusão implica na oferta de matrícula e no pleno acesso ao currículo escolar, com as adequações necessárias. Todavia, isso nem sempre ocorre, já que muitas ações pedagógicas, geralmente pautadas em uma ideia de que estudantes com TEA não podem aprender, ainda se prendem a práticas excludentes, que não levam em consideração as singularidades desses estudantes. Buscando combater essa visão e apresentar alternativas que possam contribuir para que o estudante com TEA tenha acesso pleno ao currículo escolar, o presente artigo discute resultados de uma pesquisa cujo objetivo foi compreender as contribuições das Tecnologias Digitais Educacionais para a aprendizagem matemática de estudantes com TEA. Utilizando a metodologia do estudo de caso, os dados foram produzidos a partir de encontros semanais com dois estudantes com TEA em fase inicial de escolarização e incluídos na rede regular de ensino. Os resultados aqui discutidos trazem indícios de contribuições para o desenvolvimento dos estudantes em relação à atenção compartilhada e no que tange à construção do conceito de adição. Além disso, os resultados indicam que o uso de recursos tecnológicos pode representar uma alternativa pedagógica no trabalho com esses estudantes, pois o envolvimento deles com atividades informatizadas possibilitou a construção de conceitos matemáticos que anteriormente não conseguiam em um ambiente não digital.
\end{abstract}

Palavras-chave: Recursos Tecnológicos. Práticas Inclusivas. Ensino e Aprendizagem. Educação Matemática.

\footnotetext{
Abstract

* Meste em Educação pela Universidade Federal de Alfenas (UNIFAL-MG). Professora de Educação Especial na Prefeitura Municipal de Poços de Caldas (PMPC), Poços de Caldas, Minas Gerais, Brasil. Endereço para correspondência: Praça Paulo Afonso Junqueira, 55 - Vila Cruz, Poços de Caldas, Minas Gerais, Brasil, CEP: 37701-420. E-mail:ancrisou@gmail.com.

** Doutor em Educação Matemática pela Universidade Estadual Paulista (UNESP). Docente do Programa de Pós-Graduação em Educação e do Departamento de Matemática da Universidade Federal de Alfenas (UNIFAL-MG), Alfenas, MG, Brasil. Endereço para correspondencia: Rua Gabriel Monteiro da Silva 700, Centro, Alfenas, MG, Brasil, CEP: 37130-001. E-mail: guilhermehgs2@gmail.com.
} 
The inclusion of students with Autism Spectrum Disorder (ASD), although supported by Brazilian Legislation, represents a major challenge for regular schools and it is far from being a reality. Inclusion implies the offer of enrollment and full access to the school curriculum, with the necessary adaptations. However, in general, this is not the case, since many pedagogical actions, often supported by an idea that students with ASD cannot learn, still engage in exclusionary practices that do not take into account the singularities of these students. In order to counteract this view and to present alternatives that can contribute to the ASD students' has full access to the school curriculum, this paper discusses results of a research which objective was to understand the contributions of digital educational technologies to the mathematical learning of students with ASD. Through the case study methodology, data were produced from weekly meetings with two ASD students that were in the initial phase of schooling. They were included in a regular classroom. This study shows evidence of contributions to the students' development in relation to the construction of mathematical concepts. In addition, it shows that the use of technological resources may represent a pedagogical alternative in the work with ASD students, since their involvement with computerized activities allowed for the construction of mathematical concepts that they previously could not do in a non-digital environment.

Keywords: Technological Resources. Inclusive Pedagogical Practices. Teaching and Learning. Mathematics Education.

\section{Introdução}

A inclusão de estudantes com Transtorno do Espectro Autista (TEA) na rede regular de ensino tem se intensificado ao longo dos últimos dez anos no Brasil. Segundo Schmidt et al. (2016), tal intensificação é um dos frutos da implementação de políticas de educação inclusiva, em especial da Política Nacional de Proteção dos Direitos da Pessoa com TEA (BRASIL, 2012), que assegurou a esses estudantes o direito de serem matriculados na escola regular. Essa política de macroinclusão evidencia o reconhecimento, por parte das políticas públicas brasileiras, da necessidade de proteção dos direitos da pessoa com TEA, principalmente no que diz respeito ao acesso à educação e ao ensino profissionalizante.

Ocorre que, ao se incluir, tanto políticas públicas, quanto práticas pedagógicas não devem focar simplesmente no oferecimento do acesso à educação, em todos os seus níveis de ensino. Uma concepção reconhecida e aceita atualmente considera que incluir implica igualmente no oferecimento de todos os recursos necessários para que o estudante com qualquer tipo de deficiência possa realmente se tornar um sujeito ativo em seu processo de aprendizagem e que tenha ampla oportunidade de acesso ao conhecimento historicamente e culturalmente construído (MANTOAN, 2006; CRUZ, 2014; ORRÚ, 2017).

Contudo, o que as pesquisas têm apontado é que nem sempre o processo de inclusão tem sido feito nessa perspectiva (KUPFER, 2000; SUPLINO, 2007; SERRA, 2008; GÓES, 2012; SCHMIDT et al., 2016). No caso de estudantes com TEA, o processo de inclusão, muitas vezes, acaba impondo situações que levam à invisibilidade desses estudantes no que diz respeito às suas singularidades, o que geralmente se manifesta a partir de uma visão excludente de que são incapazes de aprender (KUPFER, 2000; CAMARGO; BOSA, 2009; 
GOMES; MENDES, 2010; RODRIGUES; MOREIRA; LERNER, 2012; CRUZ, 2014).

Para combater essa visão e promover uma escolarização que realmente contemple a inclusão, consideramos a necessidade de que práticas pedagógicas inovadoras sejam adotadas, permitindo ao estudante com TEA seu desenvolvimento acadêmico e pessoal (ORRÚ, 2016). No âmbito da Educação Matemática, estudos têm sido realizados, visando contribuir nesse sentido. Por exemplo, pesquisadores têm se empenhado em discutir aspectos subjacentes ao processo de inclusão desses estudantes na rede regular de ensino, a partir das especificidades das aulas de Matemática (PRAÇA, 2011; FLEIRA, 2016). Outros vêm discutindo e desenvolvendo práticas pedagógicas e intervenções que visam favorecer a aprendizagem matemática de estudantes com TEA, tanto na escola regular, quanto nos Atendimentos Educacionais Especializados (GOMES, 2007; JORGE, 2011; CANDIDO, 2012; STRUTZ, 2015; CARDOSO, 2016; DELABONA, 2016; FLEIRA, 2016; VIANA, 2017). Não obstante, outros grupos de pesquisas têm apontado para as contribuições das Tecnologias Digitais Educacionais (TDE) no processo de ensino e aprendizagem da Matemática por estudantes com TEA, evidenciando avanços importantes nessa temática (CUNHA, 2011; CANDIDO, 2012; SANTOS; BREDA; ALMEIDA, 2015; CARVALHO; NUNES, 2016; YAKUBOVA; HUGHES; SHINABERRY, 2016).

Visando ampliar as discussões relacionadas a este último grupo, discutiremos neste artigo resultados de uma pesquisa que buscou compreender as contribuições das TDE para a aprendizagem matemática e a inclusão de estudantes com TEA, inseridos nos primeiros anos de escolarização (SOUZA, 2019). De forma específica, discutiremos resultados relacionados à construção do conceito de adição pelos estudantes que participaram da pesquisa e também apresentaremos evidências das contribuições para o desenvolvimento da atenção compartilhada. Consideramos que as implicações práticas deste trabalho possam favorecer o processo de inclusão de estudantes com TEA na escola regular, principalmente no que tange à promoção de sua aprendizagem matemática.

\section{Macroinclusão: perspectivas e desafios}

Políticas de macroinclusão visam garantir o acesso de indivíduos pertencentes a grupos marginalizados de determinados contextos, devido, frequentemente, a um passado de exclusão. Via de regra, tais políticas são impostas por lei e decretos que emergem a partir de movimentos sociais, formados por diversos segmentos e pessoas, dentre elas as próprias pessoas que compõem esses grupos (FAUSTINO et al., 2018, 2019). No contexto educacional 
brasileiro, um intenso processo de conflitos e discussões culminou no desenvolvimento de políticas de macroinclusão direcionadas à proteção da pessoa com deficiência. Podemos citar, por exemplo, a Política Nacional de Educação Especial na Perspectiva da Educação Inclusiva (BRASIL, 2008a, 2008b), que garantiu, entre outros aspectos, a inclusão de estudantes com deficiência nas escolas regulares de ensino, a criação do Atendimento Educacional Especializado (AEE), o desenvolvimento de programas de formação continuada de professores para a temática da inclusão, a reestruturação de salas de recursos e a adequação da estrutura física das escolas.

Outra política foi a Lei Brasileira de Inclusão da Pessoa com Deficiência (BRASIL, 2015), que reforçou a igualdade de oportunidades, a não discriminação e os direitos fundamentais da pessoa com deficiência, como, por exemplo, à habilitação e reabilitação, à saúde, moradia, trabalho e à educação. Especificamente no que tange aos estudantes com TEA, a promulgação da Política de Proteção dos Direitos da Pessoa com Transtorno do Espectro Autista (BRASIL, 2012) foi importante, principalmente por reconhecer a necessidade de que esses estudantes possam receber uma educação de acordo com suas particularidades.

Tendo em vista a perspectiva inclusiva que permeia as políticas de macroinclusão educacional brasileira, consideramos que o fato de assegurar a pessoas com deficiência o acesso à educação ultrapassa questões relacionadas simplesmente à sua matrícula na escola regular. Apontamos para a necessidade de que sejam ofertadas as condições para que esses estudantes possam permanecer no ambiente escolar e progredir em seu processo de aprendizagem, de modo a exercer seus direitos e sua cidadania. Acontece que, entre a legislação que propõe as políticas de macroinclusão e a prática educativa ofertada pelas escolas, existe um grande abismo que acaba por gerar diversas contradições (SUPLINO, 2007; PRAÇA, 2011; SCHMIDT et al., 2016). Isto porque, ainda hoje, algumas escolas encontram-se presas na primeira etapa do processo de inclusão. Elas ofertam o direito de matrícula, mas pouco fazem para assegurar a permanência e o sucesso desses estudantes, principalmente porque não modificam suas práticas de modo a promover uma educação voltada para as singularidades, fazendo, dessa forma, com que um local considerado inclusivo continue a promover práticas excludentes (KUPFER, 2000; SUPLINO, 2007; GOMES; MENDES, 2010; PRAÇA, 2011; ORRÚ, 2016; SCHMIDT et al., 2016). Tais práticas são chamadas por Faustino et al. (2018) de microexclusões e representam "práticas sutis, realizadas de forma consciente ou não, que tendem a 'isolar' o indivíduo em determinado ambiente, na maioria das vezes considerado inclusivo, apresentando-se como um obstáculo 
para seu desenvolvimento humano" (FAUSTINO et al., 2018, p. 900).

Faustino e colegas destacam que tais práticas podem favorecer que alguns estudantes não sejam "vistos" ou "ouvidos" pelos outros, no que tange às suas singularidades. Especificamente no que diz respeito aos estudantes com TEA, estudos têm mostrado que práticas de microexclusões vêm ocorrendo com frequência nas salas regulares de ensino, gerando situações de invisibilidade a esses estudantes (SUPLINO, 2007; CRUZ, 2014; ORRÚ, 2016). Essas práticas, que muitas vezes pairam sobre a vida dos estudantes com TEA no ambiente escolar, geralmente se conectam ao que chamamos de "Síndrome do Diagnóstico" (SOUZA; SILVA, 2019), que é toda e qualquer ação que coloca os preconceitos e o próprio diagnóstico clínico à frente de qualquer possibilidade de trabalho educativo com esses estudantes, posicionando-se à frente da própria pessoa. $\mathrm{O}$ culto ao diagnóstico encontrase vinculado a uma construção histórica que coloca a medicina, seus pareceres e carimbos como dotados de um caráter absoluto e inquestionável (ORRÚ, 2016, 2017). Orrú (2017, p. 24), por exemplo, destaca que:

\begin{abstract}
A escola se expropria da educação e dá à medicina o poder de dizer quem é que poderá ou não aprender; quem será capaz de conviver com os outros alunos; quem não conseguirá atingir os objetivos educacionais propostos pela escola; quem deve ter seu comportamento controlado para não atrapalhar os demais na sala de aula; quem deverá ser segregado, e, inclusive, quem deverá ou não receber atendimento educacional especializado.
\end{abstract}

Assim, se os manuais de medicina, como o Código Internacional de Doenças (CID), elaborado pela Organização Mundial de Saúde (OMS) (ORGANIZAÇÃO MUNDIAL DA SAÚDE, 2018), e o Manual Diagnóstico e Estatístico de Transtornos Mentais (DSM) (AMERICAN PSYCHIATRIC ASSOCIATION, 2014), definem que um estudante que possui determinada patologia é incapaz de realizar certa atividade, a Síndrome do Diagnóstico leva a escola a não considerar a humanidade e as singularidades deste e a simplesmente tomar esse diagnóstico como uma verdade absoluta, isentando-se de qualquer responsabilidade, já que não é sua função ensinar "a quem não aprende". Trata-se de uma visão preconceituosa e excludente que impede o indivíduo de fazer parte do mundo social, pois, mesmo estando em um espaço dito inclusivo, ainda encontra-se à margem, representando nada mais do que um mero número, tanto nos registros, quanto na contabilidade da escola.

A sobreposição do diagnóstico às singularidades de estudantes com TEA tem se mostrado algo constante no contexto educacional, levando-os ao isolamento e, muitas vezes, ao fracasso escolar (SUPLINO, 2007; CRUZ, 2014; ORRÚ, 2016; SCHMIDT et al., 2016). Fracasso este que já lhe é imposto desde o primeiro dia. O que vemos, portanto, é que o diagnóstico, que deveria servir de fonte de informações sobre o indivíduo e contribuir para 
que as práticas pedagógicas fossem direcionadas às suas singularidades, acaba tornando-se um instrumento de exclusão, levando a pessoa com TEA a passar por um processo que Adorno (1995) define por coisificação.

As microexclusões que levam o estudante com TEA ao processo de coisificação também podem ser percebidas quando o direito de aprender os conceitos trabalhados em sala de aula é negado ao estudante, devido à sua própria presença ser considerada apenas uma forma de socialização. Ou seja, a escola está sendo benevolente ao deixar que uma pessoa que "não aprende" esteja no meio dos demais para que possa sentir-se incluída. Especificamente com relação à aprendizagem da Matemática, esse processo torna-se ainda mais complexo, uma vez que, embora esteja presente na vida cotidiana das pessoas, ela não é concebida dessa forma pela escola, mas percebida como algo voltado "para poucos"1, dentre os quais não se encontram as pessoas com TEA, a não ser que estas sejam dotadas de alto funcionamento.

Dessa forma, poderíamos dizer que um pensamento, no imaginário das pessoas, é que, se estudantes com TEA não são capazes de se comunicar, como dizem os manuais clínicos, se não estabelecem interações sociais ou mesmo se não conseguem compreender o mundo que os cerca, vivendo sempre no isolamento, então por que razão se deveria "perder tempo" em ensinar matemática para eles? Todavia, pessoas com TEA não são incapazes de aprender, elas apenas aprendem de uma forma diferente (VYGOTSKY, 1997; KUPFER, 2000; CRUZ, 2014; ORRÚ, 2016). Cabe à escola a tarefa de encontrar essa forma, promovendo processos de compensação social. Na perspectiva da psicologia histórico-cultural, a deficiência em si não traz limitações para os sujeitos, mas cria outras formas de interagir com o mundo, que devem ser valorizadas e estimuladas por meio de processos de mediação e compensação, que possibilitarão ao estudante o desenvolvimento de suas funções superiores e, assim, ser capaz de interiorizar e se apropriar dos conceitos científicos² (VYGOTSKY, 1997).

Partindo desses princípios, consideramos que, para promover uma prática educativa que seja realmente inclusiva, necessitamos da criação de ambientes de aprendizagem que valorizem tanto a diversidade quanto as necessidades dos estudantes, buscando despertar o seu interesse pelo conhecimento, de modo que possam ser parte integrante do processo de ensino e aprendizagem (CARNEIRO, 2006). Isso leva à necessidade de que as ações educativas direcionadas aos estudantes com TEA sejam desenvolvidas a partir de seus eixos de interesses e singularidades, de modo a fornecer significado para o que está sendo

\footnotetext{
${ }^{1}$ Sobre a visão da matemática como sendo algo para poucos, veja-se a discussão em Skovsmose (2014).

${ }^{2}$ Veja-se a discussão em Souza (2019) e em Souza e Silva (2019).
} 
trabalhado (VASCONCELLOS, 1996; KUPFER, 2000; KUPFER; PETRI, 2000; MAGYAR, 2011; CRUZ, 2014; ORRÚ, 2016). Isto implica na adoção de práticas pedagógicas inovadoras e não excludentes, que deixem de focar nas inabilidades e passem a perceber e valorizar as potencialidades desses estudantes e, a partir disso, possibilitar "a imersão do aprendiz no âmbito individual e coletivo”, bem como “o prazer pelo aprender” (ORRÚ, 2016, p. 167).

Dentre as diferentes práticas inovadoras que contemplam o trabalho educativo voltado à construção de conhecimentos científicos por estudantes com TEA, o uso das Tecnologias Digitais Educacionais (TDE) tem se apresentado como uma das alternativas viáveis em uma educação verdadeiramente inclusiva (CUNHA, 2011; YAKUBOVA; HUGHES; SHINABERRY, 2016; CARVALHO; NUNES, 2016; SANTOS; BREDA; ALMEIDA, 2017). Isto porque os recursos tecnológicos e suas características podem apresentar similaridades com a forma de aprender de estudantes com TEA. Consideramos que o uso desse instrumento, aliado à mediação docente, pode ofertar possibilidades para atribuírem sentido e significado ao fazer educativo e, assim, avançar em seu processo de aprendizagem.

\section{Metodologia}

Utilizando-se de uma abordagem qualitativa, a pesquisa aqui discutida foi desenvolvida a partir da metodologia do estudo de caso, em consonância com as ideias de Creswell (2013), que a entende como uma estratégia de pesquisa. Em particular, neste estudo, esse processo gira em torno do trabalho com dois estudantes com TEA, por meio de ambientes de aprendizagem baseados nas TDE, visando à construção de seus conhecimentos matemáticos e também no que tange ao enfrentamento das microexclusões.

João e Maria (pseudônimos) estavam incluídos na rede regular de ensino nos Anos Iniciais do Ensino Fundamental e possuíam, respectivamente, nove e oito anos de idade. Maria estava no segundo ano do Ensino Fundamental e João no terceiro. Ambos os estudantes apresentavam a oralidade preservada, com baixo prejuízo em suas interações sociais com seus professores e colegas. Corroborando a literatura, o desenvolvimento da oralidade e a existência de um nível mínimo de interação acontecem uma vez que tais estudantes foram diagnosticados com TEA precocemente, fato que favoreceu que recebessem o atendimento apropriado desde então (LAMPREIA, 2007; TOMAINO; MILTENBERGER; CHARLOP, 2014; DUARTE et al., 2016).

Mesmo assim, apresentavam traços típicos do TEA, como estereotipias, dificuldades de concentração, resistência a mudanças e dificuldades com simbolização. No que diz respeito 
à Matemática, apresentavam dificuldades em compreender sequências lógicas e resolver operações simples, como adição e subtração, fato que acontece com um número considerável de estudantes com TEA (SANTOS; BREDA; ALMEIDA, 2017). Maria e João foram $\operatorname{convidados}^{3}$ a participar da pesquisa, devido ao seu interesse direcionado às tecnologias digitais, aspecto importante a ser considerado no trabalho pedagógico com estudantes com TEA (SANTOS; BREDA; ALMEIDA, 2017).

A produção dos dados ocorreu a partir de encontros semanais individuais realizados entre a primeira autora e cada participante, nos quais foram desenvolvidas atividades matemáticas selecionadas a partir dos eixos da matemática descritos pelos Parâmetros Curriculares Nacionais (PCN) (BRASIL, 1997). Estes eixos foram selecionados a partir da realidade dos estudantes e levaram em consideração suas singularidades. Durante o processo contínuo de elaboração e reelaboração das atividades pedagógicas, realizamos encontros com as professoras da turma regular em que João e Maria estavam matriculados. Elas nos relatavam os progressos e dificuldades dos estudantes durante as aulas e forneciam indicações de seus possíveis avanços no que tange à aprendizagem matemática. Essas informações foram utilizadas para complementar o processo de análise dos dados.

Foi realizado um total de 24 encontros com cada estudante, nos quais foram utilizados jogos livres, disponibilizados na internet, e também softwares de domínio público, atividades com o Kinect Xbox 360 e também por meio de um tablet. Os encontros foram realizados em momentos e locais distintos com cada estudante. O Quadro 1 detalha esses encontros, destacando a atividade trabalhada, seu objetivo e o eixo dos PCN em que nos embasamos para construir a atividade. Importante mencionar que a prática pedagógica nessas atividades foi explícita, direta e sistemática, levando em consideração a motivação individual de cada estudante e o uso de autorregulação (SANTOS; BREDA; ALMEIDA, 2017).

\begin{tabular}{|c|c|c|c|}
\hline & ATIVIDADE & OBJETIVO & EIXO DO PCN \\
\hline EM2 & $\begin{array}{l}\text { Color World - canhão de } \\
\text { cores }\end{array}$ & $\begin{array}{l}\text { Descrever oralmente a localização e } \\
\text { movimentação de pessoas ou objetos no espaço }\end{array}$ & Espaço e Forma \\
\hline EJ2 & $\begin{array}{l}\text { Jogo da memória dos } \\
\text { números }\end{array}$ & Estabelecer relação entre número e quantidade & Números e Operações \\
\hline $\begin{array}{l}\text { EM3 } \\
\text { EJ3 }\end{array}$ & Contar cubos & Estabelecer relação entre número e quantidade & Números e Operações \\
\hline $\begin{array}{l}\text { EM4 } \\
\text { EJ4 }\end{array}$ & Eu sei contar & Estabelecer relação entre número e quantidade & Números e Operações \\
\hline $\begin{array}{l}\text { EM5 } \\
\text { EJ5 }\end{array}$ & More or less & $\begin{array}{l}\text { Comparar quantidades identificando a que tem } \\
\text { mais e a que tem menos }\end{array}$ & Números e Operações \\
\hline
\end{tabular}

\footnotetext{
${ }^{3}$ A pesquisa seguiu todos os padrões éticos esperados em uma pesquisa científica, aprovado pelo comitê de ética em pesquisa da Universidade Federal de Alfenas, nº 67699417.1.0000.5142.
} 


\begin{tabular}{|c|c|c|c|}
\hline $\begin{array}{l}\text { EM6 } \\
\text { EJ6 }\end{array}$ & BlockFruits & $\begin{array}{l}\text { Identificar objetos agrupados de acordo com } \\
\text { suas características }\end{array}$ & Números e Operações \\
\hline $\begin{array}{l}\text { EM7 } \\
\text { EJ7 }\end{array}$ & $\begin{array}{ll}\text { Sequência } & \text { lógica: } \\
\text { Coelho Sabido } & \end{array}$ & Ordenar objetos de acordo com padrão & Números e Operações \\
\hline $\begin{array}{l}\text { EM8 } \\
\text { EJ8 }\end{array}$ & Coelhinho Faminto & Realizar adições simples & Números e Operações \\
\hline $\begin{array}{l}\text { EM9 } \\
\text { EJ9 }\end{array}$ & $\begin{array}{l}\text { Ler e contar } \\
\text { (tablet) }\end{array}$ & Realizar adições simples & Números e Operações \\
\hline $\begin{array}{l}\text { EM10 } \\
\text { EJ10 }\end{array}$ & $\begin{array}{l}\text { Corrida } \\
\text { Matemática }\end{array}$ & Realizar adições simples & Números e Operações \\
\hline $\begin{array}{l}\text { EM11 } \\
\text { EJ11 }\end{array}$ & Tangram & $\begin{array}{l}\text { Auxiliar na compreensão da geometria plana e } \\
\text { despertar e desenvolver a criatividade e o } \\
\text { raciocínio lógico }\end{array}$ & Espaço e Forma \\
\hline $\begin{array}{l}\text { EM12 } \\
\text { EJ12 }\end{array}$ & Quebra-cabeça & Raciocínio lógico e orientação espacial & Espaço e Forma \\
\hline $\begin{array}{l}\text { EM13 } \\
\text { EJ13 }\end{array}$ & Xbox Dança & $\begin{array}{l}\text { Interagir com o recurso tecnológico, estimular a } \\
\text { coordenação motora, lateralidade e organização } \\
\text { espacial }\end{array}$ & Espaço e Forma \\
\hline $\begin{array}{l}\text { EM14 } \\
\text { EJ14 }\end{array}$ & Xbox Dardos & $\begin{array}{l}\text { Trabalhar a coordenação visuomotora e } \\
\text { visuoespacial, bem como os conceitos de adição } \\
\text { e comparação }\end{array}$ & $\begin{array}{lr}\text { Espaço e } & \text { Forma/ } \\
\text { Tratamento } & \text { da } \\
\text { informação } & \\
\end{array}$ \\
\hline $\begin{array}{l}\text { EM15 } \\
\text { EJ15 }\end{array}$ & Xbox Tênis & $\begin{array}{l}\text { Trabalhar a coordenação visuomotora e } \\
\text { visuoespacial, bem como os conceitos de adição } \\
\text { e comparação }\end{array}$ & $\begin{array}{lr}\text { Espaço e } & \text { Forma/ } \\
\text { Tratamento } & \text { da } \\
\text { informação } & \\
\end{array}$ \\
\hline $\begin{array}{l}\text { EM16 } \\
\text { EJ16 }\end{array}$ & Circo mágico & $\begin{array}{l}\text { Reconhecer, através de jogos e brincadeiras, } \\
\text { noções de direita, esquerda, frente, atrás, de } \\
\text { costas, de lado, em cima de e embaixo de, entre } \\
\text { o primeiro e o último, tendo um ponto de } \\
\text { referência }\end{array}$ & Espaço e Forma \\
\hline $\begin{array}{l}\text { EM17 } \\
\text { EJ17 }\end{array}$ & Quebra-cabeça & Raciocínio lógico e orientação espacial & Espaço e Forma \\
\hline $\begin{array}{l}\text { EM18 } \\
\text { EJ18 }\end{array}$ & Tangram kids & $\begin{array}{l}\text { Auxiliar na compreensão da geometria plana e } \\
\text { despertar e desenvolver a criatividade e o } \\
\text { raciocínio lógico }\end{array}$ & Espaço e Forma \\
\hline EM19 & Fábrica: Coelho Sabido & Comparar tamanhos (maior/menor; baixo/alto) & Grandezas e Medidas \\
\hline EJ19 & Polygolf & $\begin{array}{l}\text { Reconhecer as formas geométricas e nomeá-las } \\
\text { de acordo com a quantidade de lados }\end{array}$ & Espaço e Forma \\
\hline EM20 & Nunca 10 & $\begin{array}{l}\text { Realizar operações matemáticas fazendo uso de } \\
\text { material dourado virtual }\end{array}$ & Números e Operações \\
\hline EJ 20 & Fábrica: Coelho Sabido & Comparar tamanhos (maior/menor; baixo/alto). & Grandezas e Medidas \\
\hline EM21 & Monsterland & $\begin{array}{l}\text { Reconhecer, através de jogos e brincadeiras, o } \\
\text { significado de direção, posição e sentido }\end{array}$ & Espaço e Forma \\
\hline EJ21 & Nunca 10 & $\begin{array}{l}\text { Realizar operações matemáticas fazendo uso de } \\
\text { material dourado virtual }\end{array}$ & Números e Operações \\
\hline EM22 & $\begin{array}{l}\text { Supermercado } \\
\text { Virtual }\end{array}$ & $\begin{array}{l}\text { Relacionar produtos que podem ser adquiridos } \\
\text { por peso e/ou por litro }\end{array}$ & Grandezas e Medidas \\
\hline $\mathrm{EJ} 22$ & UNO do Aladim & Associar figuras e cores, encontrando os iguais & Números e Operações \\
\hline EM23 & Dividindo a pizza & $\begin{array}{l}\text { Trabalhar composição e decomposição e } \\
\text { primeiras noções sobre divisão }\end{array}$ & Números e Operações \\
\hline EJ23 & Confeitando o bolo & $\begin{array}{l}\text { Identificar produtos que são consumidos por } \\
\text { peso e/ou por litro e sua utilização para } \\
\text { elaboração de um bolo }\end{array}$ & Grandezas e Medidas \\
\hline
\end{tabular}




\begin{tabular}{|l|l|l|l|}
\hline EM24 & Bloons & $\begin{array}{l}\text { Reconhecer, através de jogos e brincadeiras, o } \\
\text { significado de direção, posição e sentido }\end{array}$ & Espaço e Forma \\
\hline EJ24 & Dividindo a pizza & $\begin{array}{l}\text { Trabalhar composição e decomposição e } \\
\text { primeiras noções sobre divisão }\end{array}$ & Números e Operações \\
\hline
\end{tabular}

Quadro 1 - Descrição dos encontros realizados com os estudantes Maria (EM) e João (EJ) Fonte: Elaborado pelos autores (2019).

Todos os encontros foram registrados através de videogravações. Para tanto, foram utilizadas duas câmeras: uma ficava posicionada com foco direto nos participantes, de modo a captar suas expressões e reações durante o desenvolvimento da atividade; a outra ficava direcionada para a tela do computador, buscando capturar o desenvolvimento da atividade em si. Além da gravação dos encontros, a pesquisadora fazia anotações das situações que considerava relevantes em um caderno de campo.

Para a organização e análise dos dados produzidos nas videogravações, seguimos as etapas propostas por Powell (2015). Em um primeiro momento, os vídeos produzidos foram assistidos diversas vezes, sem pausas, interrupções ou qualquer análise, uma vez que a finalidade desta primeira etapa era favorecer a familiarização com o vídeo. Na segunda etapa, os dados obtidos foram descritos através de situações ocorridas pelo tempo e significado das atividades, buscando encontrar elementos que poderiam convergir com as questões da pesquisa, ainda dentro de uma visão macro.

Posteriormente, na terceira etapa, por meio da retomada das gravações e realizando algumas pausas, utilizamos um aplicativo de smartphone de transcrição de som para texto e identificamos e transcrevemos os eventos críticos. De posse das notas transcritas, na quarta etapa, os vídeos eram novamente assistidos, com pausas constantes e idas e vindas, buscando um olhar mais específico sobre eles, a partir da descrição dos eventos críticos. A quinta etapa constituiu-se da construção do enredo, organizando de forma criteriosa os eventos críticos. $\mathrm{Na}$ sexta etapa, eles foram categorizados e organizados, visando, na última etapa, construir a narrativa, olhando para as partes e considerando o todo e vice-versa. Em todo esse processo, o caderno de campo auxiliava no sentido de retomar situações importantes capturadas durante as atividades.

Posteriormente, fizemos a análise dos dados utilizando a metodologia proposta por Aguiar e Ozella (2006), com a construção e análise de núcleos de significação. Esse método de análise busca verificar a apropriação das significações constituídas pelo sujeito frente à realidade. O processo de análise nos permitiu a construção de dois núcleos de significação, que chamamos de Mediação Docente e Ressignificação (Quadro 2). 


\begin{tabular}{|c|c|}
\hline NÚCLEO DE SIGNIFICAÇÃO & INDICADORES FINAIS \\
\hline Mediação docente & A importância do professor \\
& Construindo o conceito de adição \\
& Conceitos geométricos \\
\hline Ressignificação & Concentração e interesses \\
& Lidando com frustrações \\
& Interpretação e atenção compartilhada \\
\hline
\end{tabular}

Quadro 2 - Núcleos de significação

Fonte: Elaborado pelos autores (2019).

Em outros trabalhos, discutimos de forma mais detalhada os indicadores finais relacionados à Importância do professor e à Construção dos conceitos geométricos, do núcleo que chamamos de Mediação Docente (SOUZA, 2019), e os indicadores Concentração e Interesses e Lidando com frustações, do núcleo Ressignificação (SOUZA, 2019; SOUZA; SILVA, 2019). Neste artigo, em particular, visando fornecer elementos para a compreensão das contribuições da TDE para a aprendizagem matemática de estudantes com TEA, discutiremos o indicador Construindo o conceito de Adição, do núcleo Mediação Docente, e o indicador Interpretação e Atenção compartilhada, do núcleo Ressignificação.

\section{Mediação e Ressignificação}

Vygotsky (2003) afirma que, durante o processo de aprendizagem, a criança desenvolve conceitos que podem ser espontâneos e científicos. Os espontâneos são adquiridos por meio das práticas cotidianas da vida pessoal do indivíduo e os científicos através do contato com o ensino formalizado sobre determinado objeto do conhecimento, sendo formados por meio da instrução formal ocorrida no ambiente escolar. Assim, ao falarmos em aprendizagem matemática, tendo em vista a formação de conceitos pela criança, podemos pensar em dois tipos de Matemática: a informal, adquirida por meio das relações que a criança realiza com seus pares em ambientes não formais de aprendizagem, por meio de brincadeiras e vivências cotidianas, e a formal, ocorrida no ambiente escolar.

Esta "matemática formal", que permite a construção de conceitos científicos, muitas vezes acaba sendo negada ao estudante com TEA, em virtude de problemas encontrados no processo de escolarização já citados anteriormente. Assim, para assegurarmos que ela ocorra e que a criança com TEA possa realmente formar seus conceitos científicos, no caso do presente estudo os relativos à Matemática, consideramos a necessidade de promoção de uma prática educativa que possibilite construções semióticas que irão possibilitar a formação desses conceitos, tudo isso por meio de uma ação mediadora. Neste sentido, Delabona (2016, p. 104) destaca que 
o conceito matemático não deve ser objeto de simples ensino/transmissão, pois se trata de uma construção mental mediada, realizada nas suas experiências significativas, considerando o contexto sociocultural do aprendiz e em uma ação mediadora entre professor, objeto e aluno(s). Desse modo, não é apenas pelo uso do código escrito e falado que a escola contribuiria para a formação de conceitos científicos pelo aluno.

Aqui aparece o papel fundamental da mediação, pois, de acordo com Vygotsky (1997), é por meio da interação mediada que o ser humano deixa de agir a partir de reflexos (advindos das funções elementares) e passa a agir de forma consciente. A significação dada pelo outro, em um primeiro momento através da ação mediadora, torna-se significação própria do sujeito, que ressignifica sua ação, sendo que as significações externas se tornam processos psicológicos internos. Segundo Vygotsky (2007), a mediação do outro possibilita à criança dar um salto qualitativo no seu desenvolvimento psicológico. Isso reforça o papel que o outro exerce no processo de constituição do sujeito, pois permite à criança a atribuição de significado às suas ações. Assim, o desenvolvimento cultural perpassa três momentos específicos: a realidade natural da criança (biológica), a realidade natural com significação para o outro e a aquisição da significação do natural, dada pelo outro, que se torna significativa para o sujeito (PINO, 2005).

O conceito de mediação, portanto, é importante para compreender e proporcionar o desenvolvimento de estudantes com TEA, uma vez que favorece que suas potencialidades não fiquem subordinadas ao aparato orgânico, mas às relações sociais que podem vir a estabelecer com seus pares, desde que sejam ofertadas as condições favoráveis, através de práticas sociais dotadas de significações (CRUZ, 2014). A mediação na escola, portanto, tem a função de criar um ambiente que favoreça a aprendizagem, elevando o nível dos estudantes a um patamar a que anteriormente não conseguiam chegar sozinhos (PRESTES, 2012). Sob esta perspectiva, todos os estudantes têm possibilidades de construir seus conhecimentos matemáticos, de modo que lhes faça sentido, principalmente porque a ação mediadora favorece que tenham oportunidades para agir sobre os objetos matemáticos e, assim, serem capazes de formar conceitos científicos cada vez mais elaborados (DELABONA, 2016).

Nosso estudo traz indícios de que os processos de mediação e o envolvimento dos estudantes com atividades informatizadas possibilitaram aos participantes uma ressignificação de suas ações, o que foi possível por meio da reorganização das ações e da consciência sobre si mesmo e sobre a realidade, do desenvolvimento de suas funções superiores e do reconhecimento de si mesmo, enquanto sujeitos da ação. Um dos indicadores deste núcleo, singular para que o estudante possa construir os conceitos científicos, foi a atenção compartilhada, que pode ser traduzida como uma habilidade de compartilhar a atenção com 
outras pessoas, a qual envolve, segundo Lampreia (2007, p. 107), quatro componentes de desenvolvimento: "o orientar-se e prestar atenção para um parceiro social; o coordenar a atenção entre pessoas e objetos; o compartilhar afeto ou estados emocionais com pessoas; o ser capaz de chamar a atenção dos outros para objetos ou eventos para compartilhar experiências". Trata-se de uma habilidade geralmente comprometida na criança com TEA, que serve, inclusive, de parâmetro para diagnosticar esse transtorno e que pode impossibilitar que ela desenvolva uma comunicação com finalidade social. Este é justamente um dos obstáculos para a aprendizagem. Ações interventivas que visam trabalhar essa habilidade são fundamentais (LAMPREIA, 2007).

Temos indícios de que ambos os estudantes, favorecidos pela mediação docente e pelas atividades desenvolvidas, apresentaram avanços significativos na atenção compartilhada, seja em nível de resposta ou quando mostravam interesse pela fala da pesquisadora e interação com o computador, ou de iniciativa, quando compartilhavam com o outro (pesquisadora) aquilo que estavam fazendo. Nos trechos das falas a seguir, João, ao encontrar dificuldades em realizar a atividade proposta, chama atenção da pesquisadora, por conta própria, e tenta estabelecer um diálogo em direção à atividade:

João: Tem uma peça faltando. Eu não estou conseguindo encontrar o sorriso. São tantas opções, qual será que é a dela? Aqui tem o cabelo, o nariz. Tia Andiara (disse em voz alta).

Pesquisadora: Oi.

João: Fala "o que houve, João?"

Pesquisadora: O que houve, João?

João: Tem uma peça faltando. Eu não estou conseguindo encontrar o sorriso.

Pesquisadora: Vamos encontrar o sorriso?

João: Sim (a pesquisadora auxiliou-o a encontrar a peça relativa à parte do sorriso, apontando para a mesma na tela).

Pesquisadora: Pronto, já resolveu. (ao localizar a peça e colocá-la no lugar).

(Gravação do encontro 17 - Atividade "Quebra-cabeça", EJ17, 2018).

Em outra situação, ao realizar a atividade "Tênis" no Kinect Xbox 360, quando realizou uma jogada, João tentou envolver a pesquisadora no que estava acontecendo, compartilhando com ela o que havia ocorrido no jogo:

Pesquisadora: Joga a bola para cima com esta mão.

(Ao rebater a bola, o fez de forma lenta. Diante disso, ela caiu fora da quadra).

João: O que houve? Foi tão rápido.

(Gravação do encontro 17 - Atividade "Xbox tênis", EJ15, 2018).

Em outra situação, diante de um erro, João também compartilhou com a pesquisadora sua ansiedade, solicitando que ela falasse palavras que o acalmassem e incentivassem a continuar a atividade.

Pesquisadora: Agora eu vou jogar um pouco (pegando a peça e intencionalmente colocandoa no local errado). Eu não consigo. 
João: Você está quase lá (observando os movimentos realizados pela pesquisadora).

(Gravação do encontro 18 - Atividade "Tangram kids" - EJ18, 2018).

João: Eu vou construir o caminhão. Ah, não (falou com o tom de voz elevado e após colocar uma peça em local incorreto). Fala "calma, João" (voltando-se para a pesquisadora).

Pesquisadora: Calma, João, falta apenas uma peça.

João: É só colocar a peça aqui. Conseguimos (ao encaixar corretamente a figura).

Pesquisadora: Muito bem, parabéns. Vamos fazer outro?

(Gravação do encontro 18 - Atividade "Tangram kids" - EJ18, 2018).

Em outros momentos, os estudantes mostraram atenção compartilhada ao prestar auxílio (orientação à pesquisadora) quando ela realizava a atividade e também quando apresentavam atividades que haviam realizado no ambiente de sala de aula.

João: Sim, vamos fazer outro joguinho juntos, eu e você. Qual será que é o jogo, Tia Andiara, conte os pedaços comigo (quando a pesquisadora tentava realizar a atividade e errava intencionalmente).

(Gravação do encontro 23 - Atividade "Confeitando o bolo" - EJ23, 2018).

Antes do início do encontro:

Maria: Tia, olha o que eu fiz (mostrando a reprodução de uma das atividades trabalhadas no computador e reproduzidas pela professora em sala de aula).

Maria: Tia, eu consegui, olha!

(Gravação do encontro 17 - Atividade "Quebra-cabeça" - EM17, 2018).

Consideramos que o avanço na atenção compartilhada e na comunicação social dos estudantes foi fruto das interações mantidas com a pesquisadora por meio das atividades e dos jogos partilhados. Da mesma forma, os laços de afetividade formados ao longo dos encontros foram importantes para a inclusão e uma maior interação deles nas atividades, expandindo seu repertório comunicativo com vistas a uma referenciação social.

\section{A construção de conceitos matemáticos por estudantes com TEA}

Como já mencionado, os estudantes que participaram deste estudo possuíam dificuldades com o conceito de adição durante seu processo de escolarização, fato que as professoras da escola regular nos relatavam em detalhes. Elas nos ressaltaram inicialmente que João e Maria tinham dificuldades em compreender os princípios da adição simples (com números de apenas um dígito), mesmo contando com o auxílio de material concreto (tampinhas e palitos) e com o apoio delas durante as aulas.

Dessa forma, antes de iniciarmos as atividades relacionadas à adição, optamos por trabalhar com uma série de atividades que evidenciassem o nível de desenvolvimento dos estudantes no que diz respeito à fase pré-aritmética, que representa um conjunto de prérequisitos necessários à aquisição de habilidades matemáticas relacionadas à adição (PRADO; 
CARMO, 2004). Buscávamos verificar se tais habilidades encontravam-se ou não desenvolvidas e interiorizadas pelos estudantes. Segundo Prado e Carmo (2004), isso é importante para conhecer o estudante e o seu nível de desenvolvimento, para depois introduzir novos conceitos (neste caso, as adições simples).

As atividades escolhidas para essa primeira etapa, que ocorreu nos encontros de 3 a 7 , contemplaram as habilidades pré-aritméticas de contagem até 10 e comparação simples entre conjuntos (termo a termo); uso de numerais; processos complexos de seriação, comparação de conjuntos e sequência lógica. Os resultados obtidos nos trouxeram indícios de que ambos os estudantes já possuíam interiorizadas e desenvolvidas tais habilidades. Lippman (2009) aponta a existência dessas habilidades como sendo as seguintes: um para um, ordem estável, irrelevância, cardinalidade e abstração. A partir disso, iniciamos uma nova etapa de trabalho, buscando a construção do conceito de adição. Nesta foram desenvolvidas as atividades correspondentes aos encontros 8,9 e 10 .

No primeiro desses encontros, tivemos o objetivo de identificar se, no ambiente informatizado, as dificuldades apresentadas pelos estudantes em relação à adição eram similares àquelas que possuíam na sala de aula regular. Iniciamos com uma atividade desenvolvida através do jogo "O Coelho Faminto", cujo objetivo era resolver adições simples disponibilizadas na tela do computador. A representação das somas era feita tanto através de números quanto de figuras. Após realizar a soma, o estudante deveria selecionar com o cursor do mouse o valor correspondente ao resultado, escolhendo um dos números disponibilizados abaixo da operação (de 1 até 10). Quando o estudante acertava a questão, recebia um feedback ${ }^{4}$ positivo, escrito em um balão ao lado do coelho, e imediatamente um novo balão se abria e uma nova operação era sorteada, sendo que uma cenoura aparecia nas mãos do coelho. Quando a resposta estava incorreta, o resultado selecionado pelo estudante desaparecia da tela, ficando apenas os demais números.

Iniciamos a atividade explicando para os estudantes que iríamos auxiliar o "Coelho Faminto" a ganhar cenouras, mas, para isso, deveríamos somar as frutas que estavam aparecendo na tela ${ }^{5}$. No desenvolvimento da atividade com João, foi possível constatar que, em um primeiro momento, ele não percebia a operação matemática contida no jogo, apesar de mostrar que entendia o conceito de conversação. Nessa atividade, João só conseguiu

\footnotetext{
${ }^{4}$ Segundo Santos (2018, p. 38), feedbacks são importantes no trabalho pedagógico com estudantes com TEA, "no sentido de orientá-las na realização das tarefas, apoiar a compreensão do comportamento do ambiente digital e prever o comportamento de características ou elementos semelhantes".

${ }^{5}$ As explicações e forma de apresentação e condução da atividade foram as mesmas para ambos os estudantes, todavia, conforme já destacado, foram realizadas em momentos e locais distintos.
} 
compreendê-la com o auxílio da pesquisadora, que foi realizando com ele o passo a passo da operação, contando, primeiramente, o número de frutas da primeira parcela e apontando para a tela e, posteriormente, os da segunda parcela, para, finalmente, somar todas as frutas. Para tanto, a pesquisadora apontava para a fruta colocando seus dedos sobre a tela do computador e fazendo sua contagem em voz alta, o que era acompanhado por João. No trecho a seguir, destacamos um desses momentos.

Pesquisadora: Quantas frutas o coelho tem? (na tela havia a seguinte adição: $1+3$ ).

João: (pausa e silêncio) Uma maçã, três laranjas.

Pesquisadora: E quantas frutas ele tem ao todo, contando as maçãs e as laranjas?

João: (novamente fez silêncio e ficou olhando para a tela do computador, sem nada dizer).

(Gravação do encontro 8 - Atividade "O Coelho Faminto" - EJ8, 2018).

A pesquisadora apontou então para as frutas da tela e solicitou que ele contasse juntamente com ela. Assim, ambos chegaram ao resultado da operação. A atividade continuou a ser desenvolvida dessa forma. Maria, por sua vez, necessitou de auxílio para realizar as primeiras operações, todavia, a partir da quinta operação compreendeu a ideia da adição por meio da contagem um a um e conseguiu realizar a atividade com autonomia. Para efetuar as operações descritas no jogo, fazia primeiramente contando a quantidade do conjunto de frutas 1 (maçãs, por exemplo), depois a quantidade de frutas 2 (laranjas) e, em seguida, realizava a contagem de ambos, o que fazia contando com o apoio visual das frutas disponibilizadas logo acima dos números componentes da operação matemática representada:

Pesquisadora: Vamos contar primeiro as maçãs e depois as laranjas. Quantas maçãs tem?

Maria: Um, dois, três.

Pesquisadora: Quantas laranjas?

Maria: Um, dois, três, quatro.

Pesquisadora: Vamos contar quantas frutas ele tem juntas?

Maria: Três maçãs.

Pesquisadora: Conta todas.

Maria: Um, dois, três, quatro, cinco, seis, sete (contando junto com a pesquisadora). É o sete da Maria.

Pesquisadora: Clica para ver o resultado, está correto?

Maria: Sim. Sete.

(Gravação do encontro 8 - Atividade "O Coelho Faminto" - EM8, 2018).

E, mais tarde, realizando a atividade sozinha:

Pesquisadora: Agora esse você fará sozinha.

Maria: Um, dois, três (fazendo a contagem de todas as maçãs).

Maria: Um, dois (fazendo a contagem das laranjas).

Maria: Um, dois, três, quatro, cinco (fazendo a contagem de todas as frutas).

Maria: Cinco (selecionou com o cursor do mouse o número 5).

Pesquisadora: Parabéns, você acertou. Vamos para o próximo (Maria deu um sinal afirmativo com a cabeça).

(Gravação do encontro 8 - Atividade "O Coelho Faminto" - EM8, 2018). 
A forma como realizaram a atividade sugere que ambos os estudantes encontravam-se no primeiro nível de compreensão da adição, que Gray e Tall (1994) definem como "contatodos", pois contaram um primeiro grupo de objetos, em seguida contaram um segundo grupo e, finalmente, contaram todos. Esta situação destaca a existência dessa habilidade pelos estudantes, a qual não havia sido percebida na sala de aula com materiais concretos (tampinhas e palitos). Isso pode ser uma evidência de que o ambiente informatizado possibilita o desenvolvimento de estratégias pedagógicas que favoreçam que as necessidades dos estudantes sejam contempladas, uma vez que evita distrações, como tampinhas caindo no chão, por exemplo, e auxilia na aprendizagem, tendo em vista o apelo visual, que, conforme já destacado, é um aspecto importante no trabalho com estudantes com TEA (GRANDIN, 2000; MOORE, 2005; MAGYAR, 2011; SALVADOR, 2012; TARBOX et al., 2014).

Outro fator que também contribuiu para a compreensão da atividade pelos participantes foi a inserção de figuras correspondentes às quantidades próximas ao símbolo numérico, uma vez que a utilização de imagens, símbolos, pictogramas, ícones de áudio ou vídeo colocados próximo ao texto correspondente facilita a compreensão simbólica (SANTOS; BREDA; ALMEIDA, 2017). Além disso, o próprio ambiente de aprendizagem possibilitado pelo uso do computador, limpo de distrações, com comandos diretos, objetivos e previsíveis, pode ser considerado fator que favoreceu o desenvolvimento dos estudantes, fato que corrobora outros estudos (CARVALHO; NUNES, 2016; CAMINHA; CAMINHA; ALVES, 2016; SANTOS; BREDA; ALMEIDA, 2017).

A fim de atestarmos as primeiras impressões, obtidas no encontro anterior, e buscando contribuir para o desenvolvimento das competências relacionadas à realização de adições simples, optamos por trabalhar com atividades semelhantes nos dois encontros subsequentes. No encontro 9, trabalhamos o jogo "Ler e Contar" em um tablet. O objetivo foi o de realizar adições simples a partir de um jogo de dominó. Na tela eram apresentadas duas peças de dominó contendo os pontos correspondentes à quantidade de elementos e, abaixo destas, três números, sendo que um deles era o que respondia corretamente à questão e os outros dois não. O estudante deveria, então, realizar a operação e selecionar, com um toque de seus dedos, a resposta correta. Quando os estudantes acertavam, o jogo trazia uma tela com feedback afirmativo dizendo "Você acertou" e soltava vários balões que poderiam ser estourados pelos estudantes utilizando os dedos. Quando erravam, uma tela com feedback negativo, emitindo um sinal sonoro semelhante ao de uma campainha, deixava em vermelho a resposta errada e dizia "Você errou". Fazendo uso das pistas visuais, João e Maria realizaram a atividade com autonomia e sem a necessidade de intervenção, ainda realizando a contagem do tipo conta- 
todos.

No encontro 10, optamos por trabalhar com um jogo com apenas a operação numérica, sem a representação através de pistas visuais (desenhos). O jogo escolhido foi "Corrida Matemática”, que também trabalhava adições simples. Consistia de uma corrida de carros em que o estudante movimentava seu carro a partir da resolução correta das operações disponibilizadas na tela. Após realizar a operação, o estudante deveria selecionar, com o cursor do mouse, o número correspondente ao resultado disponibilizado do lado direito da tela. Ante a resposta correta, o carro se movia para frente. Caso contrário, ficava parado no lugar. Após concluir corretamente todas as respostas, o carro ultrapassava a linha de chegada e o estudante recebia um troféu digital pelo seu desempenho.

No início da atividade, por não terem mais o apoio visual, ambos os estudantes sentiram dificuldades para realizar a operação, necessitando da intervenção da pesquisadora. Primeiramente, conversamos com eles, explicando que poderíamos utilizar as mãos para representar os números, dizendo que cada mão representaria uma parcela da adição: o número que estava antes do sinal de adição seria representado na mão esquerda e o número após o sinal, na mão direita Assim, faríamos a soma. Para exemplificar, fizemos a primeira operação representando com nossas próprias mãos. Depois passamos a fazê-lo representando junto com os estudantes e fazendo uso de suas mãos.

Pesquisadora: Vamos fazer assim: o número que está antes do sinal nós vamos fazer com a mão esquerda e o que está depois com a direita (fazendo com as mãos). Agora vamos somar.

João: Um, dois, três (nesta mão) e um, dois na outra. Um, dois, três, quatro, cinco.

Pesquisadora: Agora você.

João: Cinco mais dois.

Pesquisadora: E quanto dá?

João (após realizar a representação nas mãos, fez a contagem): Um, dois, três, quatro, cinco, seis, sete. Sete.

Pesquisadora: E quanto é agora?

João: Imediatamente fez a representação e contagem: um, dois, três (representando dois em uma mão e um na outra).

Pesquisadora: Muito bem.

João: Vamos para outra?

(Gravação do encontro 10 - Atividade "Corrida Matemática" - EJ10, 2018).

Maria: Mais quatro, mais dois.

Pesquisadora: Mais quatro, mais dois? Olha o que ele está pedindo. Quatro mais quatro. Faz com suas mãos.

Maria: Um, dois, três, quatro, cinco, seis, sete, oito (representando cada parcela em uma mão).

Pesquisadora: Ele andou?

Maria: Só um pouquinho.

Pesquisadora: É que temos que fazer mais operações. O que ele pediu?

Maria: Um mais quatro.

Pesquisadora: Faz com suas mãos. 
Maria: Um mais quatro (representando com as mãos); um, dois, três, quatro, cinco. Muito bem.

Pesquisadora: Agora você sozinha.

Ao aparecer a operação na tela, Maria imediatamente fez a representação com as mãos.

Pesquisadora: Dois mais três. Um, dois, três, quatro, cinco.

(Gravação do encontro 10 - Atividade "Corrida Matemática" - EM10, 2018).

Após a primeira etapa, ambos os estudantes já haviam compreendido a sistemática da operação e conseguiram realizar as operações de forma autônoma. Nesta atividade, os estudantes não mais realizaram a contagem do tipo conta-todo, mas a contagem efetiva (FERREIRA, 2012), pois representavam, na mão esquerda, a primeira quantidade e, quando faziam na segunda, não mais representavam para depois contar, ou seja, quando representavam eles já incorporavam o número ao fato conhecido e realizavam a sobrecontagem, utilizando os elementos da outra mão. Por exemplo, contavam três, quatro, cinco e seis e não mais um, dois, três e um, dois, três, para depois contar um, dois, três, quatro, cinco, seis - tal fato é um indício de uma possível evolução no seu processo de contagem.

Segundo Ferreira (2012), o uso dos dedos das mãos no processo de contagem é algo comum e importante na construção da noção de adição, pois auxilia as crianças a contextualizarem seu raciocínio, estabelecendo uma relação entre a linguagem oral e os símbolos matemáticos (FERREIRA, 2012). Estas relações, de acordo com Castro e Rodrigues (2008) e Brocardo et al. (2005), facilitam o cálculo mental e a compreensão do sentido das operações.

Ferreira (2012) também destaca que, além da utilização dos dedos das mãos como recurso auxiliar, o uso de materiais concretos, como tampinhas, palitos, etc., pode favorecer o desenvolvimento da contagem. Contudo, a experiência prévia desses estudantes em sala de aula com tais materiais, como já mencionamos, não auxiliou nesse sentido, pois, segundo seus professores da turma regular, eles se perdiam na contagem e não conseguiam manter a concentração, o que gerava crises por não terem o controle total dos materiais (por exemplo, quando as tampinhas deslizavam pela mesa sem a vontade deles ou mesmo quando caíam no chão).

Para nós, o uso dos dedos das mãos permitiu autonomia a João e Maria e, mais do que isso, favoreceu o controle deles da situação, algo importante no trabalho pedagógico com crianças com TEA. Nesse sentido, o fato de conseguirem representar as quantidades somadas nas mãos e também efetuarem as adições sem interferência da pesquisadora, pode ser um indício de que eles internalizaram e se apropriam dos conceitos matemáticos trabalhados. 
A formação dos conceitos matemáticos pelos estudantes foi ancorada no processo de mediação por meio do diálogo e troca de experiências entre os estudantes e a professora pesquisadora, apoiados nas facilidades fornecidas pelo ambiente informatizado, que possibilitaram a organização e estruturação da atividade, tornando-a previsível e objetiva para os estudantes.

De acordo com Moore (2005), isso representa uma das melhores adaptações educacionais que podem ser fornecidas aos estudantes com TEA, uma vez que evita mudanças e bagunças capazes de gerar ansiedade e desencadear suas estereotipias. Isso pode ser constatado por meio da fala das professoras, que nos relataram que, todas as vezes em que não conseguiam realizar a operação de adição, por se confundirem com o material concreto e se "perderem" na execução das atividades, os estudantes recorriam às suas estereotipias (ecolalia verbal e agitação de uma garrafa plástica, no caso de João) ou apresentavam comportamentos autoagressivos (beliscar as mãos, no caso de Maria).

Além disso, a capacidade de realizar adições simples com independência, ainda que fazendo uso das mãos, representa indícios de que os estudantes avançaram no desenvolvimento de suas funções superiores, ampliando seu nível de desenvolvimento real (VYGOTSKY, 1997). Isso pode ser percebido uma vez que, no início dos encontros, ambos os estudantes não conseguiam, mesmo com auxílio, realizar operações de adição simples; depois conseguiram realizá-las com auxílio, para finalmente fazê-las com autonomia, entrando no que Treffers (2001) define como primeiro nível de cálculo (cálculo por contagem), que representa a etapa inicial da aprendizagem da adição e da subtração, sendo apoiados por materiais que possibilitam a contagem.

\section{Considerações finais}

Ao longo deste estudo, apontamos que a inclusão de estudantes com TEA na rede regular de ensino, em que pese a existência das políticas de macroinclusão, ainda está distante de ser uma realidade nas escolas. Isto porque ainda paira sobre eles um estigma de incapacidade, perpetuado por visões e práticas excludentes que, muitas vezes, têm como fundamento a Síndrome do Diagnóstico. Isso faz com que estudantes com TEA, mesmo em um espaço chamado inclusivo, ainda se encontrem à margem do processo de escolarização.

Superar esta visão exige uma mudança de paradigmas que possibilite um olhar diferenciado sobre o estudante com TEA e suas potencialidades, percebendo-o como um sujeito capaz de aprender e que possui habilidades e competências que devem ser conhecidas 
e valorizadas. A partir do conhecimento e valorização das singularidades do estudante com TEA, a escola pode desenvolver uma prática educativa inovadora e não excludente, fornecendo reais possibilidades de participar ativamente do processo de construção do conhecimento.

Os resultados encontrados neste estudo trazem indícios de que o uso de recursos tecnológicos pode representar uma alternativa para que a escola promova esse tipo de prática, pois o envolvimento dos estudantes com atividades informatizadas possibilitou a eles a construção de conceitos matemáticos que não conseguiam em um ambiente não digital. Além disso, forneceu sentido e significado aos estudantes e, assim, contribuiu para que se tornassem autores de sua aprendizagem, o que pode implicar na efetivação de sua inclusão e no combate às microexclusões, uma vez que tiveram voz e visibilidade a partir do respeito de suas singularidades e interesses.

Uma importante implicação da pesquisa se deu a partir da relação entre as professoras da sala de aula regular e o Atendimento Educacional Especializado (AEE). Como já mencionamos, esta pesquisa se desenvolveu a partir do trabalho com dois estudantes com TEA durante horário de AEE, o que, desde 2012, é um direito assegurado a esses estudantes. Os resultados aqui discutidos reforçam a importância deste atendimento para sua inclusão no ambiente escolar de estudantes com TEA. Segundo Faustino et al. (2019), uma microexclusão comumente praticada com estudantes incluídos na escola regular ocorre quando professores transferem para o AEE a responsabilidade da Educação Matemática desses estudantes. No caso do presente estudo, a postura das professoras da turma regular em que João e Maria estavam incluídos foi diferente, pois, como já destacamos, durante as reuniões regulares que realizávamos com as professoras, discutíamos os avanços e as dificuldades dos estudantes, tanto no AEE, quanto na escola regular, visando elaborar as atividades que seriam trabalhadas.

Esse contato próximo com as professoras permitiu, por exemplo, que as professoras adaptassem muitas das atividades que foram realizadas no AEE e as utilizassem com todos os estudantes da sala regular. Além disso, outra implicação importante foi que as professores nos relataram que os recursos informatizados passaram a fazer parte da rotina de João e Maria também na sala de aula regular. Maria ganhou um computador e João um notebook, que passaram a ser utilizados por eles durante suas aulas. Segundo as professoras, isso proporcionou maior participação dos estudantes durante as atividades desenvolvidas no contexto escolar. Ademais, afirmaram que todos os alunos da turma de João passaram a ter aulas semanais utilizando recursos digitais. 


\section{Referências}

ADORNO, T. Educação e Emancipação. Rio de Janeiro: Paz e Terra, 1995.

AGUIAR, W. M. J.; OZELLA, S. Núcleos de significação como instrumento para a apreensão da constituição dos sentidos. Psicologia: Ciência e Profissão, Brasília, v. 26, n. 2, p. 222-245, jun. 2006.

AMERICAN PSYCHIATRIC ASSOCIATION. Manual Diagnóstico e Estatístico de Transtornos Mentais: DSM-5. American Psychiatnc Association. Tradução de Maria Inês Corrêa Nascimento et al. Porto Alegre: Artmed, 2014.

BRASIL. Parâmetros Curriculares Nacionais: Matemática (Ministério da Educação, Secretaria de Educação Fundamental). Brasília: MEC/SEF, 1997.

. Política Nacional de Educação Especial na Perspectiva da Educação Inclusiva. Brasília: Ministério da Educação, 2008a.

Decreto $\mathrm{n}^{\mathbf{0}}$ 6.571, de 2008. Dispõe sobre o atendimento educacional especializado, regulamenta o parágrafo único do Art. 60 da Lei n ${ }^{\circ}$ 9.394, de 20 de dezembro de 1996, e acrescenta dispositivos ao Decreto $n^{\circ}$ 6.253, de 13 de novembro de 2007. Diário Oficial da União, Brasília, 18 set. $2008 \mathrm{~b}$.

. Lei 12.764, de 2012. Institui a Política Nacional de Proteção dos Direitos da Pessoa com Transtorno do Espectro Autista e altera o $\S 3^{\circ}$ do art. 98 da Lei n. 8.112, de dezembro de 1990. Brasília, 2012. Disponível em: http://www.planalto.gov.br/ccivil_03/_ato20112014/2012/lei/112764.htm. Acesso em: 15 ago. 2017.

Lei $\mathbf{N}^{\circ}$ 13.146, de 6 de julho de 2015. Dispõe sobre a Lei Brasileira de Inclusão da Pessoa com Deficiência. Brasília, 2015. Disponível em: <ttp://www.planalto.gov.br/ccivil_03/_Ato20152018/2015/Lei/L13146.htm> Acesso em: 04 ago. 2017.

BROCARDO, J. et al. Desenvolvendo o Sentido do Número: Perspectivas e Exigências Curriculares. Lisboa: Associação de Professores de Matemática, 2005.

CAMARGO, S. P. H.; BOSA, C. A. Competência social, inclusão escolar e autismo: revisão crítica da literatura. Psicologia \& Sociedade, Florianópolis, v. 21, n. 1, p. 65-74, 2009.

CAMINHA, V. L.; CAMINHA, A. D. O.; ALVES, P. P. Ambiente Digital de Aprendizagem para crianças autistas (ADACA). In: CAMINHA, V. L. et al. (Org.). Autismo: vivências e caminhos. São Paulo: Edgard Blücher, 2016. p. 123-137.

CANDIDO, V. M. A. A fazenda" e a lógica matemática: tecnologia no processo de aprendizagem de crianças autistas. 2012. 82f.. Trabalho de Conclusão de Curso (Especialização em Novas Tecnologias e Educação) - Universidade da Paraíba, Paraíba, 2012.

CARDOSO, D. M. P. Funções executivas: habilidades matemáticas em crianças com Transtorno do Espectro Autista (TEA). 2016. 160 f. Tese (Doutorado em Educação) -Faculdade de Educação, Universidade Federal da Bahia, Salvador, 2016.

CARNEIRO, M. S. C. A deficiência mental como produção social: de Itard à abordagem históricocultural. In: BAPTISTA, C. R.; BEYER, H. O. (Org.). Inclusão e escolarização: múltiplas perspectivas. Porto Alegre: Mediação, 2006. p. 137-152.

CARVALHO, O. M. F.; NUNES, L. D. O. P. Possibilidades do uso de jogos digitais com criança autista: estudo de caso. In: CAMINHA, V. L. et al. (Org.). Autismo: Vivências e Caminhos. São 
Paulo: Edgar Blücher, 2016. p. 77-90.

CASTRO, J. P.; RODRIGUES, M. O sentido de número no início da aprendizagem. In: BROCARDO, J.; SERRAZINA, L.; ROCHA, I. O sentido do número: reflexões que entrecruzam teoria e prática. Lisboa: Escolar Editora, 2008. p. 117-133.

CRESWELL, J. W. Qualitative inquiry and research design: choosing among five approaches. 3 ed. Los Angeles: SAGE Publications, 2013.

CRUZ, T. Autismo e inclusão: Experiências no Ensino Regular. Jundiaí: Paco Editorial, 2014.

CUNHA, R. M. Desenvolvimento e avaliação de um jogo de computador para ensino de vocabulário para crianças com autismo. 2011. $111 \mathrm{f}$. Dissertação (Mestrado em Informática) Pontifícia Universidade Católica do Rio de Janeiro, Rio de Janeiro, 2011.

DELABONA, S. C. A mediação do professor e a aprendizagem de geometria plana por um aluno com Transtorno do Espectro Autista (Síndrome de Asperger) em um laboratório de matemática escolar. 2016. 194 f. Dissertação (Mestrado em Ensino na Educação Básica) - Universidade Federal de Goiás, Goiânia, 2016.

DUARTE, C. P. et al. Diagnóstico e intervenção precoce no transtorno do espectro do autismo: Relato de um caso. In: CAMINHA, V. L. et al. (Org.). Autismo: vivências e caminhos. São Paulo: Edgar Blücher, 2016. p. 46-56.

FAUSTINO, A. C. et al. Macroinclusão e microexclusão no contexto educacional. Revista Eletrônica de Educação, São Carlos, v. 12, n. 3, p. 898-911, set./dez. 2018.

. Microexclusion in Inclusive Mathematics Education. In: KOLLOSCHE, D. et al. (Org.). Inclusive Mathematics Education: State-of-the-Art Research from Brazil and Germany. Cham: Springer, 2019. p. 55-70.

FERREIRA, E. O desenvolvimento do sentido de número no âmbito da resolução de problemas de adição e subtração no 2. ${ }^{\circ}$ ano de escolaridade. 2012. $587 \mathrm{f}$. Tese (Doutorado em Educação) Universidade de Lisboa, Lisboa, 2012.

FLEIRA, R. C. Intervenções pedagógicas para a inclusão de um aluno autista nas aulas de matemática: um olhar Vygotskyano. 2016. 136 f. Dissertação (Mestrado em Educação) - Programa de Pós-Graduação Strictu Sensu em Educação, Universidade Anhanguera de São Paulo, São Paulo, 2016.

GÓES, R. S. A escola de educação especial: uma escolha para crianças autistas e com deficiência intelectual associada de 0 a 5 anos. 2012. 86f. Dissertação (Mestrado em Psicologia Escolar e do Desenvolvimento Humano) - Instituto de Psicologia, Universidade de São Paulo, São Paulo, 2012.

GOMES, C. G. S. Autismo e ensino de habilidades acadêmicas: adição e subtração. Revista Brasileira de Educação Especial, Marília, v. 13, n. 3, p. 345-364, set./dez. 2007.

GOMES, C. G. S.; MENDES, E. G. Escolarização inclusiva de alunos com autismo na rede municipal de ensino de Belo Horizonte. Revista Brasileira de Educação Especial, Marília, v. 16, n. 3, p. 375$396,2010$.

GRANDIN, T. Teaching tips for children and adults with autism. USA: [s.n], 2000. Disponível em: www.autism.org. Acesso em: 30 mar. 2017.

GRAY, E. M.; TALL, D. O. Duality, ambiguity and flexibility: A perceptual view of simple arithmetic. 
Journal for Research in Mathematics Education, Reston, v. 26, n. 12, p. 115-141, 1994.

JORGE, E. V. As possibilidades e os desafios da utilização do lúdico para a aprendizagem em matemática de educando com síndrome de Asperger. 2011. 92 f. Dissertação (Mestrado em Ensino de Ciências Naturais e Matemática) - Centro de Ciências Exatas e Naturais, Universidade Regional de Blumenau, Blumenau, 2011.

KUPFER, M. C. M. Educação para o futuro: psicanálise e educação. São Paulo: Escuta, 2000.

KUPFER, M. C. M.; PETRI, R. Por que ensinar a quem não aprende? Estilos da Clínica, São Paulo, v. 5 , n. 9 , p. 109-117, 2000.

LAMPREIA, C. A perspectiva desenvolvimentista para a intervenção precoce no autismo. Estudos de Psicologia, Campinas, v. 24, n. 1, p. 105-114, 2007.

LIPPMANN, L. Matemática para educação infantil. Curitiba: IESDE, 2009.

MAGYAR, C. Developing and Evaluating Education Programs for Students with Autism. New York: Springer, 2011.

MANTOAN, M. T. E. Inclusão escolar: O que é? Por quê? Como fazer? São Paulo: Moderna, 2006.

MOORE, S. T. Síndrome de Asperger e a escola fundamental: soluções práticas para dificuldades acadêmicas e sociais. Tradução de Inês de Souza Dias. São Paulo: Associação Mais 1, 2005.

ORGANIZAÇÃO MUNDIAL DA SAÚDE. Classificação Estatística Internacional de Doenças e Problemas Relacionados à Saúde: CID 11. 2018.

ORRÚ, S. E. Aprendizes com autismos: aprendizagem por eixos de interesse em espaços não excludentes. Petrópolis: Vozes, 2016.

O re-inventar da inclusão: os desafios da diferença no processo de ensinar e aprender. Petrópolis: Vozes, 2017.

PINO, A. As marcas do humano: As origens da constituição cultural da criança na perspectiva de Lev S. Vigotski. São Paulo: Cortez, 2005.

POWELL, A. B. Métodos de pesquisa em Educação Matemática: usando escrita, vídeo e internet. Campinas: Mercado de Letras, 2015.

PRAÇA, E. T. P. O. Uma reflexão acerca da inclusão de aluno autista no ensino regular. 2011. 140 f. Dissertação (Mestrado Profissional em Educação Matemática) - Instituto de Ciências Exatas, Universidade Federal de Juiz de Fora, Juiz de Fora, 2011.

PRADO, P. S. T.; CARMO, J. S. Fundamentos do comportamento matemático: A importância dos prérequisitos. In: HÜBNER, M. M. C. M.; MARIOTTI, M. (Org.). Análise do Comportamento para a Educação: contribuições recentes. Santo André: Esetec, 2004. p. 137-157.

PRESTES, Z. R. Quando não é quase a mesma coisa: traduções de Lev Semionovitch Vigotski no Brasil. Campinas: Autores Associados: 2012.

RODRIGUES, I. D. B.; MOREIRA, L. E. D. V.; LERNER, R. Análise institucional do discurso de professores de alunos diagnosticados como autistas em inclusão escolar. Psicologia: Teoria e Prática, São Paulo, v. 14, n. 1, p. 70-83, 2012. 
SALVADOR, N. Autismo: deslizando nas ondas. Porto Alegre: AGE, 2012.

SANTOS, M. I.; BREDA, A.; ALMEIDA, A. M. Ambiente digital de aprendizagem promotor do desenvolvimento do raciocínio matemático de alunos com Perturbações do Espectro do Autismo. In: CONFERÊNCIA INTERNACIONAL DE TIC NA EDUCAÇÃO, 15, 2015, Braga, Portugal. Anais... Braga: Universidade do Minho, 2015. p. 854-865.

Design approach of mathematics learning activities in a digital environment for children with autism spectrum disorders. Education Technology Research and Develoment, New York, v. 65, p. 1305-1323, oct. 2017.

SANTOS, M. I. G. As tecnologias digitais no apoio ao desenvolvimento do raciocínio matemático de alunos com Perturbação do Espetro do Autismo. 2018. 387 f. Tese (Doutorado em Multimídia em Educação) - Departamento de Educação, Universidade de Aveiro, Aveiro, 2018.

SCHMIDT, C. et al. Inclusão escolar e autismo: uma análise da percepção docente e práticas pedagógicas. Psicologia: Teoria e Prática, São Paulo, v. 18, n. 1, p. 222-235, 2016.

SERRA, D. Entre a esperança e o limite: um estudo sobre a inclusão de alunos com autismo em classes regulares. 2008. 124 f. Tese (Doutorado em Psicologia) - Departamento de Psicologia, Pontifícia Universidade Católica do Rio de Janeiro, Rio de Janeiro, 2008.

SKOVSMOSE, O. Um convite à educação matemática crítica. Tradução de Orlando de Andrade Figueiredo. Campinas: Papirus, 2014. (Coleção Perspectivas em Educação Matemática)

SOUZA, A.C. O uso de tecnologias digitais educacionais para o favorecimento da aprendizagem matemática e inclusão de estudantes com transtorno do espectro autista em anos iniciais de escolarização. 2019. 162 f. Dissertação (Mestrado) - Universidade Federal de Alfenas, Alfenas, 2019.

SOUZA, A. C.; SILVA, G. H. G. Autism Spectrum Disorder and Mathematics Education: Possibilities with Students from Elementary School. In: KOLLOSCHE, D. et al. (Org.). Inclusive Mathematics Education: State-of-the-Art Research from Brazil and Germany. Cham: Springer, 2019. p. 295-314.

SUPLINO, M. H. F. O. Retratos e Imagens das vivências inclusivas de dois alunos com autismo em classes regulares. 2007. 172 f. Tese (Doutorado em Educação) - Faculdade de Educação Universidade Estadual do Rio de Janeiro, Rio de Janeiro, 2007.

STRUTZ, E. Autismo: aprendizagem baseada em problemas com foco na inclusão. 2015. $61 \mathrm{f}$. Dissertação (Mestrado em Ensino de Ciências Naturais e Matemática) - Centro de Ciências Exatas e Naturais, Universidade Regional de Blumenau, Blumenau, 2015.

TARBOX, J.; DIXON, D. R.; STURMEY, P.; MATSON, J. L. Early Intervention for Austim Spectrum Disorders. Cham: Springer, 2014.

TOMAINO, M. E.; MILTENBERGER, C. A.; CHARLOP, M. H. Social Skills and Play in Children with Autism. In: TARBOX, J. et al. (Org.). Handbook of Early Intervention for Autism Spectrum Disorders: Research, Policy, and Practice. New York: Springer, 2014. p. 437-452.

TREFFERS, A. Grade 1 (and 2): Calculation up to 20. In: HEUVEL-PANHUIZEN, M. V. (Org.). Children Learn Mathematics. Netherlands: Freudenthal Institute Utrecht University \& National Institute for Curriculum Development, 2001. p. 43-60.

VASCONCELLOS, F. Da estereotipia ao significante: movimentos a partir de um tratamento em instituição. Estilos da Clínica, São Paulo, v. 1, n. 1, p. 46-57, 1996. 
VIANA, E. A. Situações didáticas de ensino da matemática: um estudo de caso de uma aluna com transtorno do espectro autista. 2017. 94 p. Dissertação (Mestrado em Educação Matemática) Instituto de Geociências e Ciências Exatas, Universidade Estadual Paulista, Rio Claro, 2017.

VYGOTSKY, L. S. Obras Escogidas: Tomo V. Madrid: Visor, 1997. 2003. Pensamento e linguagem. Tradução de Jefferson Luiz Camargo. São Paulo: Martins Fontes, . A formação social da mente. São Paulo: Martins Fontes, 2007.

YAKUBOVA, G.; HUGHES, E. M.; SHINABERRY, M. Learning with technology: video modeling with concrete-representation-abstract sequencing for students with Autism Spectrum Disorder. Journal of Autism Development Disorder, New York, v. 46, n. 7, p. 2349-2362, 2016.

Submetido em 13 de Dezembro de 2018. Aprovado em 07 de Agosto de 2019. 